\title{
A STUDY ON UTILIZATION OF ANGIOTENSIN-CONVERTING ENZYME INHIBITORS AND ANGIOTENSIN RECEPTOR BLOCKERS IN PATIENTS WITH CARDIOVASCULAR DISEASES
}

\author{
ANUROOP SOOD ${ }^{1}$, JISMI JOSEPH ${ }^{1}$, SNEHA MATHEW ${ }^{1}$, SUBRAMANYAM K ${ }^{2}$, RAJESH KS ${ }^{1 *}$, BHARATH RAJ KC ${ }^{1}$
}

${ }^{1}$ Department of Pharmacy Practice, NGSM Institute of Pharmaceutical Sciences, Nitte (Deemed to be University), Mangaluru, Karnataka, India. ${ }^{2}$ Department of Cardiology, K. S. Hegde Medical Academy, Nitte (Deemed to be University), Mangaluru, Karnataka, India.

Email: rajeshks@nitte.edu.in

Received: 15 June 2018, Revised and Accepted: 07 August 2018

ABSTRACT

Objectives: The objective of this study was to assess the prescribing pattern, most common indication, and adverse effects associated with angiotensinconverting enzyme inhibitors (ACEIs) and angiotensin receptor blockers (ARBs) in patients with cardiovascular diseases, and to identify the risk factors associated with cardiovascular diseases in a tertiary care hospital.

Methods: A prospective observational study was carried out for a period of 6 months from October 2016 to March 2017 in both inpatients and outpatients of the cardiology department. Patients received either ACEIs or ARBs were enrolled in the study. The relevant details of the patients were collected from the patient case note and treatment chart and data analyzed.

Results: Of 100 patients, $23.0 \%$ were female and $77.0 \%$ were male. Among them, majority of patients were in the age group of 41-60 years. Diabetes mellitus (39\%), smoking (20\%), and alcohol (14\%) were the common risk factors. The most common indications of ACEIs were found to be ischemic heart diseases (IHDs) (17\%) followed by hypertension (HTN)/IHD (12\%), and IHD/heart failure (12\%). Main indications of ARBs were found in HTN/ IHD (16\%). Utilization of ACEIs (70\%) was found to be higher when compared with ARBs (30\%). Ramipril (69\%) and telmisartan (18\%) were the most commonly used ACEIs and ARBs, respectively. While analyzing the adverse effects of ACEIs and ARBs, about 5.71\% of patients were identified with ramipril induced dry cough.

Conclusions: The complications of cardiovascular diseases can be reduced by knowing the incidence of risk factors and alternative therapy can be initiated by assessing the incidence of adverse drug reactions related to ACEIs and ARBs

Keywords: Angiotensin-converting enzyme inhibitors, Adverse drug reactions, Angiotensin receptor blockers, Cardiovascular diseases, Drug utilization, Risk factors.

(c) 2018 The Authors. Published by Innovare Academic Sciences Pvt Ltd. This is an open access article under the CC BY license (http://creativecommons. org/licenses/by/4. 0/) DOI: http://dx.doi.org/10.22159/ajpcr.2018.v11i12.27974

\section{INTRODUCTION}

Cardiovascular disease is a general category of disease that affects the heart and the circulatory system [1]. Cardiovascular diseases are leading cause of morbidity and mortality in India [2]. According to the study conducted by the World Health Organization (WHO) in 2002, cardiovascular diseases will be the largest cause of death and affliction by 2020 in India [3]. Recent trends indicate that the disease has escalated to younger age group also, and it is present in both male and female in urban and rural population [4]. In the United Kingdom, about one-third of men and one quarter of women are dying due to ischemic heart disease (IHD). When compared with Eastern Europe and Asia, the incidence of IHD has been reduced in the developed countries from the last 20 to 30 years [5].

The various risk factors for cardiovascular diseases include diabetes mellitus (DM), smoking, family history, obesity, alcohol, and age. It is necessary to control all these risk factors which may otherwise lead to various cardiovascular complications such as IHD, stroke, and chronic renal failure [6].

Angiotensin-converting enzyme inhibitors (ACEIs) and angiotensin receptor blockers (ARBs) are among the common therapeutic options in the treatment of various cardiovascular diseases such as heart failure (HF), hypertension (HTN), stroke, mitral valve regurgitation (MR), aortic regurgitation (AR), myocardial infarction, and IHDs $[7,8]$.

The WHO defines drug utilization as "the marketing, distribution, prescription, and use of drugs in society, with special emphasis on the resulting medical, social, and economic consequences" [9]. Drug utilization studies are an important tool to examine the use of drug in a society [10].

The WHO defines adverse drug reaction (ADR) as "any response to a drug which is noxious (or) unintended, and which occurs at doses normally used in man for prophylaxis, diagnosis, or therapy of disease or the modification of physiological function" [11]. These ADRs can be minimized by creating awareness among the professionals [12]. The various adverse effects caused by ACEIs include dry cough, angioedema, dizziness, hypotension, and hyperkalemia and those due to ARBs include angioedema, hypotension, and hypoglycemia [13]. The current study aims to analyze the prescription pattern, to identify the most common indications of ACEIs and ARBs, to identify the risk factors associated with cardiovascular diseases, and to evaluate the incidence of ACEIs and ARBs induced adverse effects in patients with cardiovascular diseases associated with the Department of Cardiology at a Charitable Tertiary Care Hospital.

\section{METHODS}

This was a prospective observational study conducted in a charitable tertiary care teaching hospital for a period of 6 months (October 2016-March 2017). The study was approved by the institutional ethics committee (REF: INST. EC/EC/104/2016-2017). The subjects included both inpatients and outpatients of either gender with age 18 years and above, receiving ACEIs and/or ARBs at cardiology department. 
Patients' demographic details such as patients IP number, age, gender, date of admission, date of discharge, weight, height, BMI, complaints on admission, medical and medication history, alternative medications, diagnosis, risk factors, and the generic and brand names of the medications the patient is on, especially ACEIs and/or ARBs during the course of study were noted along with their indications, dose, frequency, and route of administration. Documentation form was prepared to record the ADRs related to ACEIs and ARBs. The recorded details were assessed using causality, Naranjo scale.

The data collected was compiled, tabulated in Microsoft Excel 2013. Quantitative variables were described as mean \pm SD, and categorical variables were described as frequencies and percentages. Association of risk factors with cardiovascular diseases was tested using Chi-square test. $\mathrm{p} \leq 0.05$ will be considered as statistical significance. Data were analyzed using Statistical Package for the Social Sciences version 16.0 for windows.

\section{RESULTS}

\section{Demographic status of study population}

A total of 100 patients were included in this study. Of which 23 (23.0\%) were female and 77 (77.0\%) were male. In our study, male predominance was noted over female. The mean age of the study population was found to be $59.36 \pm 9.22$ years. Among them, majority of the patients are under the age group of $41-60(51 \%)$ years, and the other age distributions are provided in Fig. 1.

\section{Incidence of risk factors}

The most common risk factors associated with study population were found to be DM (39\%) followed by smoking (20\%), alcohol (14\%), family history (6\%), and obesity (4\%) (Fig. 2).

\section{Association of risk factors with cardiovascular diseases}

Among the study population, the association between risk factors and cardiovascular disease were obtained by using Chi-square test. The results show some significant association between the cardiovascular diseases and risk factors as given in Table 1.

\section{Indications of ACEIs and ARBs among the study population}

The various indications of ACEIs and ARBs are shown in Table 2.The common indications of ACEIs were found to be IHD (17\%) followed by HTN/IHD (12\%), IHD/HF (12\%), IHD/HF/HTN (9\%), IHD/MR/HF/ HTN (5\%), HF/HTN (4\%), HTN (3\%), HF/MR (2\%), MR (2\%), IHD/MR (1\%), HTN/MR/IHD (1\%), HF (1\%), and AR (1\%). The indications of ARBs were found as follows: HTN/IHD (16\%), IHD/HTN/HF (4\%), HTN (4\%), IHD (3\%), HTN/AR (2\%), and IHD/MR/HF/HTN (1\%).

Distribution patterns of ACEIs and ARBs in study population

The distribution patterns of ACEIs and ARBs indicate that majority of the study population were prescribed with ACEIs (70\%) and ARBs (30\%) (Fig. 3.1).

Among the 70 patients prescribed with ACEIs, the main two ACEIs prescribed including ramipril (69\%) and enalapril (1\%). Of 30 prescribed with ARBs, the three different ARBs include telmisartan (18\%), losartan (8\%), and olmesartan (4\%) (Fig. 3.2).

\section{Incidence of ADRs related to ACEIs and ARBs}

The main adverse effect was found as dry cough associated with ACEIs (5.71\%). Causality assessment was done using Naranjo scale, and the assessment shows that the ADR was probable (Fig. 4).

\section{DISCUSSION}

In the current study, the results reveal that of 100 patients, the frequency of the use of ACEIs and ARBs was more in male patients $(77.0 \%)$ than female patients $(23.0 \%)$. Similar results were shown in accordance with the study conducted by Vakade et al. [14]. However, contradictory results were shown by the study conducted by Barrron et al. [15].
Table 1: Association between risk factors and cardiovascular disease

\begin{tabular}{llll}
\hline S. No & $\begin{array}{l}\text { Risk } \\
\text { factors }\end{array}$ & $\begin{array}{l}\text { Cardiovascular } \\
\text { diseases }\end{array}$ & p value \\
\hline 1 & Smoking & HF & 0.044 \\
& & IHD+HTN+MR & 0.044 \\
2 & DM & IHD+HTN+HF & 0.017 \\
3 & Obesity & HTN+IHD & 0.033 \\
& & HF+HTN & 0.029 \\
4 & Alcohol & HF & 0.013 \\
& & AR & 0.013 \\
\hline
\end{tabular}

HF: Heart failure, IHD: Ischemic heart diseases, HTN: Hypertension, MR: Mitral regurgitation, AR: Aortic regurgitation

Table 2: Indication of ACEIS and ARBs

\begin{tabular}{llll}
\hline S. No & Indications & $\begin{array}{l}\text { ACEIs (\% of } \\
\text { drug used) }\end{array}$ & $\begin{array}{l}\text { ARBs (\% of } \\
\text { drug used) }\end{array}$ \\
\hline 1 & HTN & 3 & 4 \\
2 & IHD & 17 & 3 \\
3 & HF & 1 & 0 \\
4 & MR & 2 & 0 \\
5 & AR & 1 & 0 \\
6 & HTN+AR & 0 & 2 \\
7 & IHD+MR & 1 & 0 \\
8 & HF+MR & 2 & 0 \\
9 & HTN+IHD & 12 & 16 \\
10 & IHD+HF & 12 & 0 \\
11 & HF+HTN & 4 & 0 \\
12 & IHD+HTN+MR & 1 & 0 \\
13 & IHD+HF+HTN & 9 & 4 \\
14 & IHD+MR+HF+HTN & 5 & 1 \\
& Total & 70 & 30 \\
\hline
\end{tabular}

ACEIS: Angiotensin-converting enzyme inhibitors, ARBs: Angiotensin receptor blockers, HTN: Hypertension, IHD: Ischemic heart diseases, HF: Heart failure, MR: Mitral regurgitation, AR: Aortic regurgitation

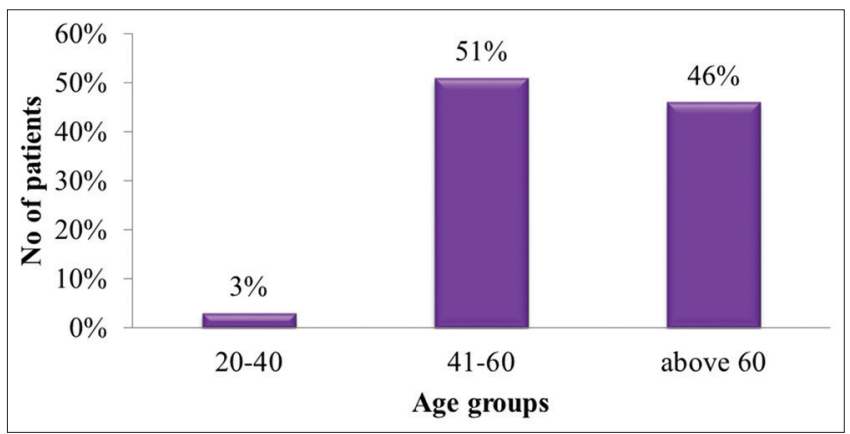

Fig. 1: Age-wise distribution

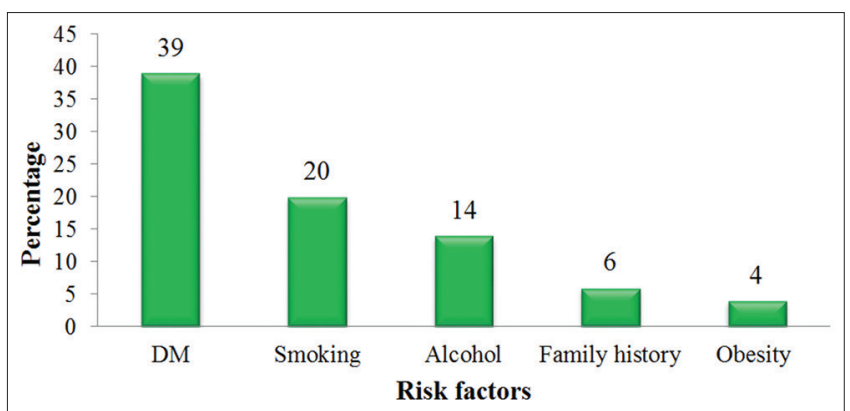

Fig. 2: Incidence of risk factors within the study population

The present study, maximum numbers of patients were in the age group of 41-60 years. As far as age factor is concern, $3 \%$ patients belong to 


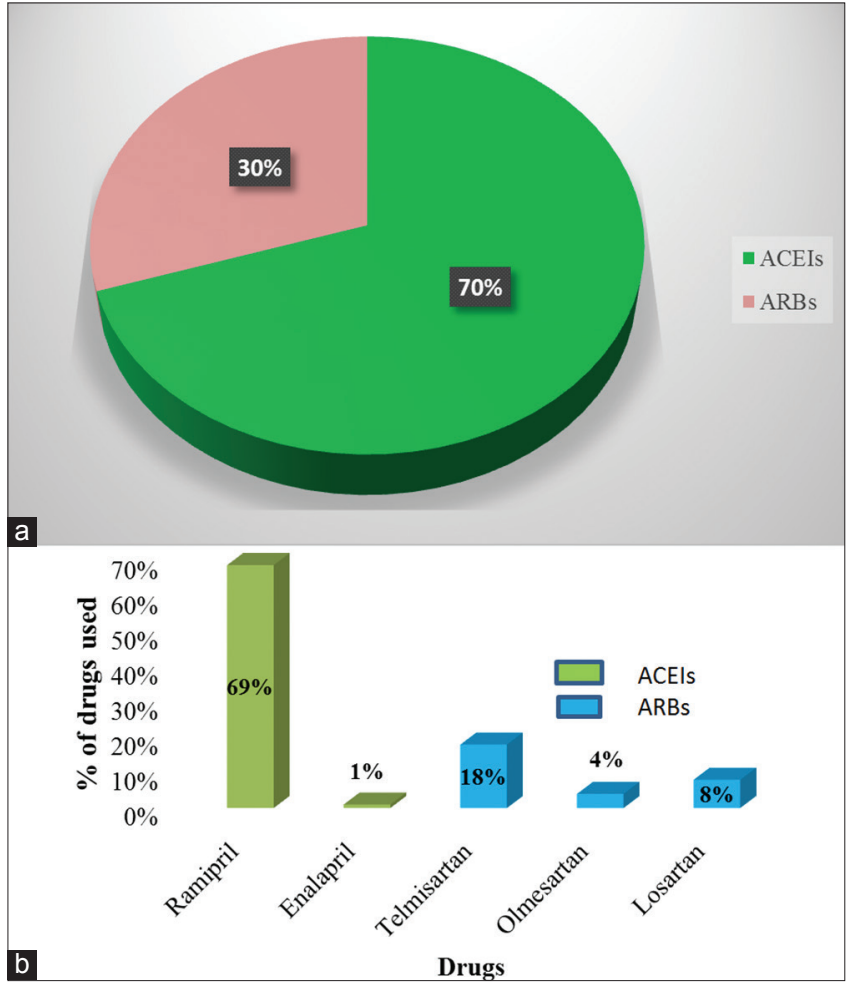

Fig. 3(a and b): Percentage of angiotensin-converting enzyme inhibitors and angiotensin receptor blockers used

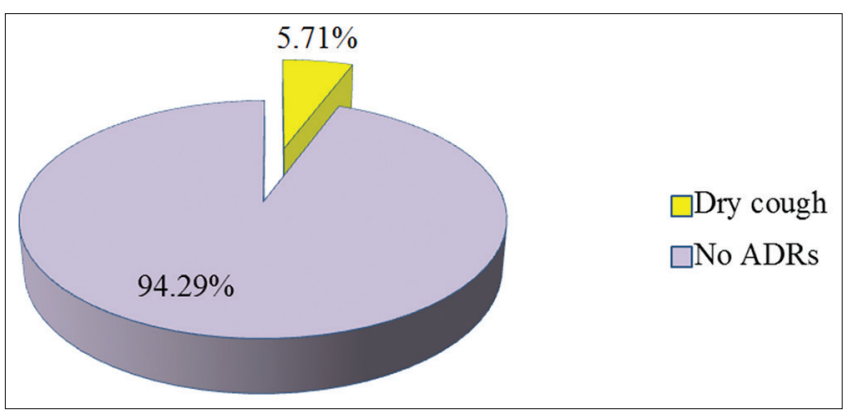

Fig. 4: Incidence of angiotensin-converting enzyme inhibitors induced cough

the age group of $20-40$ years, $51 \%$ patients belong to the age group of $41-60$ years, and $46 \%$ are $>60$ years [7]. Similar results were shown by the studies conducted earlier $[10,16,17]$.

The current study shows that the most common risk factors associated with study population were found to be DM (39\%) followed by smoking (20\%), alcohol (14\%), family history (6\%), and obesity (4\%). Similar results were obtained from several studies which include a study conducted by Pereira et al. [18] shows that incidence of DM was less when compared to our study and obesity was found to be same and other studies by Baskota et al. [19] show that the incidence of alcohol intake was less and the incidence of smoking was more when compared to our study.

Of 100 patients studied, the most common indications of ACEIs were found to be IHD (17\%) followed by HTN/IHD (12\%), IHD/HF (12\%), IHD/HF/HTN (9\%), IHD/MR/HF/HTN (5\%), HF/HTN (4\%), HTN (3\%), HF/MR (2\%), MR (2\%), IHD/MR (1\%), HTN/MR/IHD (1\%), HF $(1 \%)$, and AR (1\%), and the indications of ARBs were found as follows: HTN/IHD (16\%), IHD/HTN/HF (4\%), HTN (4\%), IHD (3\%), HTN/AR $(2 \%)$, and IHD/MR/HF/HTN (1\%). Similar results were obtained from the study conducted by Healey et al. shows that ACEIs and ARBs were indicated for AF, post-MI, HF, and HTN. In another study conducted by Deszi et al. [7] shows that ACEIs were used in the treatment of CHF, post-AMI, and CAD. ARBs are used only as a substituent if there is any ACEIs intolerance.

The result indicated that majority of the study population were prescribed with ACEIs (70\%) and ARBs (30\%). Among 70\% of patients, mainly two ACEIs were prescribed, namely ramipril (69\%) and enalapril (1\%). The other $30 \%$ of patients were prescribed with ARBs, namely telmisartan (18\%), losartan (8\%), and olmesartan (4\%). When comparing the result with other studies; the use of ACEIs was found to be more than that of ARBs in the present study $[15,18]$. A similar result was shown by Vakade et al. that ramipril was the most commonly used ACEIs [20]. Contrasting results were shown in other study conducted by Matteti et al. [6]. Among the ACEIs, perindopril was most commonly used followed by lisinopril and ramipril [21]. According to the study conducted by Vakade et al. [14], olmesartan was the commonly used ARBs.

While analyzing the patients who receive ACEIs and ARBs show dry cough (5.71\%), as the main adverse effects associated with ACEIs. Similar results were found in a study conducted by Nazir et al. [22]. In another study conducted by Pereira et al. shows that the prevalence of cough was more in patients receiving ACEIs.

\section{CONCLUSIONS}

In this study, we identified that ACEIs and ARBs show clinical benefits when used in the treatment of various cardiovascular diseases such as IHD, HTN, HF, MR, and AR and we found that ACEIs are the commonly prescribed class of drugs than ARBs. ARBs were prescribed only in patients who do not tolerate ACEIs. Ramipril and telmisartan were the most commonly used ACEIs and ARBs, respectively, and the complications of cardiovascular diseases can be reduced by knowing the incidence of risk factors such as DM, smoking, family history, obesity, and alcohol intake.

Considering the other ADRs, cough is the most commonly occurred ADR with ACEIs, and an alternative therapy can be initiated by assessing the incidence of ADR related to ACEIs and ARBs. The overall study results help to determine the use of drug in the society and to avoid the inappropriate drug use.

\section{ACKNOWLEDGMENT}

We would like to express sincere gratitude the authorities of NItte (Deemed to be University), Mangaluru, NGSM Institute of Pharmaceutical Sciences, Mangaluru, and Justice KS Hegde Hospital, Mangaluru, for providing all the facilities for this study. We also thank Mr. Krishna Bhat, Statistician, and Nitte (deemed to be University) for his timely suggestions.

\section{AUTHORS' CONTRIBUTIONS}

Rajesh KS, Subramanyam K, and Bharath Raj KC provided the study design and the data were collected and tabulated by AnuroopSood, Jismi Joseph, and Sneha Mathew. Subramanyam K, Bharath Raj KC, AnuroopSood, Jismi Joseph, and Sneha Mathew analyzed and interpreted the results, and Bharath Raj KC, AnuroopSood, Jismi Joseph, and Sneha Mathew prepared the manuscripts and all authors approved the final manuscript.

\section{CONFLICTS OF INTEREST}

The authors declare that they have no conflicts of interest.

\section{REFERENCES}

1. Muhit A, Rahman O, Raihan SZ, Asadurzzman M, Akbar MA, Sharmir N, et al. Cardiovascular disease prevalence and prescription pattern at a tertiary level hospital in Bangladesh. J Appl Pharm Sci 
2012;2:80-4

2. Chauhan S, Aeri BT. Prevalence of cardiovascular diseases in India and its economic impact: A review. Int J Sci Res Publ 2013;3:1-5.

3. WHO. National Cardiovascular Diseases. Available from: http://www. searo.who.int/india/topics/cardiovascular_diseases/en/. [Last accessed on 2017 Mar 26].

4. Kradjan WA. Cardiac and vascular disorders. In: Koda-Kimble MA, Young LY, Alldredge BK, Corelli RL, Gaglielma BJ, Kradjan WA, et al editors. Applied Therapeutics: The Clinical Use of Drugs. $9^{\text {th }}$ ed. New York: Lippincott Williams and Wilkin's; 2009. p. 18-35.

5. Newby DE, Grubb NR, Bradbury A. Cardiovascular diseases. In: Walker ID, Colledge NR, Ralston SH, Penman ID, editors. Davidson's Principles and Practice of Medicine. 22 $2^{\text {nd }}$ ed. New York: Churchill Livingstone Elsevier; 2014. p. 528.

6. Matteti UV, Cidda M, Batchu MK, Martha S. Study of prescribing pattern of antihypetensives in South India population. Int J Basic Clin Pharmacol 2014;3:303-7.

7. Deszi CA. Different therapeutic choices with ARBs. Am J Cardiovasc Drug 2016;16:255-66.

8. Rajasekhar DG, Prasanna GU, Chandrakanth P. Prescribing pattern of antihypertensive drugs based on compelling indications with hypertension. Int J Pharm Pharm Sci 2015;8:72-5.

9. WHO. Introduction to Drug Utilization Research. Available from: http://www.apps.who.int/medicinedocs/en/d/Js4876e/. [Last accessed on 2017 May 7].

10. Zafar F, Ali H, Naveed S, Korai OU, Rizvi M, Naqui GR, et al. Drug utilization pattern in cardiovascular diseases: A descriptive study in tertiary care setting in Pakistan. J Bioequiv Availab 2015;7:59-62.

11. WHO- International Drug Monitoring the Role of National Centre. Geneva: Technical Report Series WHO; 1972. p. 498.

12. Kumar L. Pharmacovigilance/reporting adverse drug reactions: An approach to enhance health surveillance and extending market share by minimizing the chances of drug withdrawals. Int J Pharm Pharm Sci 2015;7:1-7.
13. Mahmoud SH, Asselberg FW, Keyser CE, Sooverein PC, Hofman A, Stricker $\mathrm{BH}$, et al. Change in prescription pattern as a potential marker for adverse drug reactions of angiotensin converting enzyme inhibitors. Int J Clin Pharm 2015;37:1095-103.

14. Vakede KP, Thorat MV, Khanwelkar CC, Jadhav SA, Sanghishetti VM. A study of prescribing pattern of drugs in patients of cardiovascular emergencies at a tertiary care hospital of Western Maharashtra. Int J Res Med Sci 2016;4:556-61

15. Barron HV, Michael AD, Maynard C, Every NR. Use of angiotensin converting enzyme inhibitors at discharge in patients with acute myocardial infarction in United States: Data form from the national registry of myocardial infarction. J Am Coll Cardiol 1998;32:360-70.

16. Gregorie F, Pariente A, Reglat AF, Haramburu F, Begaud B, Moore N. A signal of increased risk of hypoglycaemia with angiotensin receptor blocker caused by confounding. Br J Clin Pharmacol 2008;66:142-5.

17. Kumar M, Dahiya V, Mishra S, Sharma D, Mishra N, Lahkar M. Cardiovascular disease prevalence and drug utilisation pattern at a tertiary care hospital in north-eastern India. Int J Pharm Pharm Sci 2016;8:116-9.

18. Sandozi T, Nausheen F. Drug utilisation study in ischemic heart diseases associated with diabetes and hypertension. Int J Pharm Bio Sci 2010;1:1-4.

19. Baskota M, Rao BS, Shakya R. Study on the prescribing patterns of drugs used in heart failure. J Sci Eng Technol 2006;2:1-10.

20. Al-Mallah MH, Tleyeh IM, Ahamed A, Latif A, Weaver WD. Angiotensin-converting enzyme inhibitors in coronary artery disease and preserved left ventricular systolic function. J Am Coll Cardiol 2006;47:1576-83.

21. Lee HY, Cooke CE, Robertson TA. Use of secondary prevention drug therapy in patients with acute coronary syndrome after hospital discharge. J Manage Care Pharm 2008;14:271-80.

22. Nazir A, Sheikh FM, Aslam S, Javaid U. ACE inhibitors; comparison of ACE inhibitors (perindopril, ramipril and lisinopril) induced cough. Prof Med J 2016;23:1145-8 